\title{
Inhibitory effect of municipal sewage on symbiosis between mangrove plants and arbuscular mycorrhizal fungi
}

\author{
Yutao Wang ${ }^{1,2,3}$, Qiu Qiu ${ }^{4}$, Shaoshan Li $^{2}$, Guorong Xin ${ }^{1, *}$, Nora Fung-yee Tam ${ }^{5,6, *}$ \\ ${ }^{1}$ Guangdong Key Laboratory of Plant Resources, Key Laboratory of Biodiversity Dynamics and Conservation of Guangdong \\ Higher Education Institutes, School of Life Sciences, Sun Yat-sen University, Guangzhou 510275, PR China \\ ${ }^{2}$ Key Laboratory of Ecology and Environmental Science in Guangdong Higher Education, School of Life Sciences, \\ South China Normal University, Guangzhou 510631, PR China \\ ${ }^{3}$ Guangdong Provincial Key Laboratory of Environmental Pollution Control and Remediation Technology, \\ Guangzhou 510275, PR China \\ ${ }^{4}$ Guangzhou Water Quality Monitoring Center, Guangzhou 510010, PR China \\ ${ }^{5}$ Department of Biology and Chemistry, City University of Hong Kong, Hong Kong SAR \\ ${ }^{6}$ State Key Laboratory in Marine Pollution, City University of Hong Kong, Hong Kong SAR
}

\begin{abstract}
The impact of municipal sewage discharge on the symbiosis between arbuscular mycorrhizal fungi (AMF) and mangrove plants in different sections along 2 constructed mangrove belts was evaluated. Each section was $33 \mathrm{~m}$ long and $3 \mathrm{~m}$ wide and planted with Kandelia obovata or Aegiceras corniculatum, the 2 most common mangrove plants in South China. A greenhouse experiment comparing the colonization intensity of AMF among different mangrove plant species under wastewater treatment was also conducted. Typical arbuscular mycorrhiza structures were observed in most of the root samples collected from the constructed belts. In both belts, the AMF colonization intensities were significantly lower in the roots of plants close to the inlet than in those further away from the influent, suggesting that the colonization intensity of AMF was inhibited by municipal sewage discharge, and that inhibition was least pronounced in the effluent where the concentration of nutrients was lowest. AMF colonization intensities in the roots of $A$. corniculatum were significantly higher than those in the roots of $K$. obovata, which could be attributed to the fact that $A$. corniculatum provided more oxygen to support the AMF than did K. obovata, indicating the strong effects of the host species on AMF colonization. In both constructed wetland belts and greenhouse experiments, the AMF vesicle and arbuscular structures (the main functional structure of arbuscular mycorrhiza) appeared to be more sensitive to wastewater discharge than the hyphal structure, implying that sewage discharge would reduce the potential beneficial effects of AMF in mangrove ecosystems. This study provides useful information on the responses of AMF to sewage; this knowledge is important for the conservation and restoration of mangrove forests that are located close to human activities.
\end{abstract}

KEY WORDS: Aegiceras corniculatum - Arbuscular mycorrhizal fungi · AMF · Constructed wetland $\cdot$ Kandelia obovata $\cdot$ Wastewater

\section{INTRODUCTION}

Arbuscular mycorrhizal fungi (AMF, phylum Glomeromycota) are associated with over two-thirds of plant species in a symbiotic interaction known as

${ }^{*}$ Corresponding authors: lssxgr@mail.sysu.edu.cn, bhntam@cityu.edu.hk arbuscular mycorrhiza (AM), which is the most ecologically and agriculturally important symbiosis in terrestrial ecosystems (Fitter et al. 2011). In exchange for photosynthates provided by plant symbionts, fungal partners improve plant access to phosphorus, 
nitrogen and other nutrients (Smith \& Read 2008). The presence and composition of AMF species can profoundly affect the diversity and productivity of plant communities on land (van der Heijden et al. 2008). In addition to their widespread distribution and functional significance in terrestrial ecosystems, the presence of AMF in wetland habitats has also been reported (Wilde et al. 2009, Wang et al. 2011). Colonization of AMF in wetland plants also produces a wide range of benefits to their plant partners (Miller \& Sharitz 2000, Wang et al. 2010), suggesting the importance of AMF in wetland ecosystems.

Mangrove forests are important wetlands in intertidal zones that are located in tropical and subtropical regions. They create unique ecological environments that host rich assemblages of species, and they also protect and stabilize coastlines, enrich coastal waters, yield commercial forest products and support coastal fisheries (Das \& Vincent 2009). Despite their great ecological significance, global mangrove areas are declining rapidly, mainly due to inappropriate anthropogenic activities (Polidoro et al. 2010). In China, mangrove forests are mostly distributed in southern coastal regions (Lin 1999). During the past $50 \mathrm{yr}$, large areas of these mangrove forests have been cleared for coastal development, urban construction and aquacultures, and total mangrove area has been severely reduced, from approximately 40000 ha in the 1950s to 15000 ha in the 1990s (Lin 1999). In recent years, local and national governments have paid more attention to protection and restoration programs for mangrove forests in these regions. AMF could significantly improve the growth of mangrove plants through the enhanced absorption of nutrients and other elements (Wang et al. 2010). Several studies have shown that AMF are ubiquitous in mangrove habitats despite the saline and micro-aerobic conditions in the rhizosphere of mangrove plants (Sengupta \& Chaudhuri 2002, Wang et al. 2011, D'Souza \& Rodrigues 2013a,b).

Mangrove forests, due to their proximity to dense human populations and inadequate protection, often receive domestic sewage and other types of wastewater (Polidoro et al. 2010, Wang et al. 2013). Information on the impacts of municipal sewage discharge on mangrove plants (Herteman et al. 2011), ciliate communities (Chen et al. 2009), crab and mollusc assemblages (Cannicci et al. 2009) and soil enzymes (Yang et al. 2008) have previously been published; however, the impact of wastewater on the symbiosis between AMF and mangrove plants remains unexplored. In terrestrial ecosystems, the inhibitory effects of high levels of phosphorus (P) and/or nitrogen $(\mathrm{N})$ on the symbiosis between AMF and plants have been widely studied (van Diepen et al. 2011, Lin et al. 2012). There is also solid evidence showing that excess organic matter can be harmful to this symbiotic relationship (Sáinz et al. 1998). However, an appropriate application of organic matter could promote AMF colonization in host species (Hodge \& Fitter 2010). So far, the effect of excess nutrients or organic matter on the symbiosis between wetland plants and AMF remains poorly understood.

We evaluated the impact of municipal sewage discharge on the symbiosis between AMF and mangrove plants. The colonization intensity of AMF and the density of AMF spores in 6 sections, along 2 constructed mangrove belts planted with Kandelia obovata and Aegiceras corniculatum, were investigated. A greenhouse experiment was also conducted to compare the colonization intensity of AMF between 2 host mangrove species under wastewater treatment and control.

\section{MATERIALS AND METHODS}

\section{Expt 1: Investigation of AMF in 2 constructed mangrove wetland belts}

\section{Constructed mangrove wetland belts}

Two subsurface-flow, constructed, mangrove belts for treating municipal sewage were built as a field trial in the Futian Nature Reserve of Shenzhen in South China $\left(22^{\circ} 32^{\prime} \mathrm{N}, 114^{\circ} 03^{\prime} \mathrm{E}\right)$. Each constructed mangrove belt was $33 \mathrm{~m}$ in length, $3 \mathrm{~m}$ in width and $0.5 \mathrm{~m}$ in height and filled with stones (bottom, $20 \mathrm{~cm}$ deep), gravel (20 cm deep) and a mixture of mangrove soil and sand (surface, $10 \mathrm{~cm}$ deep). No sterilization procedure was applied to the stone, gravel, sand and mangrove soil used for wetland construction. Two native mangrove species, Kandelia obovata Sheue Liu \& Yong [previously known as Kandelia candel and renamed after Sheue et al. (2003)] and Aegiceras corniculatum L. Blanco, were selected as the test plants because of their great potential for natural wastewater treatment (Wong et al. 1997) and wide distribution in the mangrove habitats of China. One-year-old individuals of each of the 2 mangrove species were transplanted into each belt in May 2005 , with a distance interval of $0.5 \mathrm{~m}$ between individual plants. Three months after transplanting, wastewater collected from the surrounding premises was discharged into the inlet of each belt after settling in a sedimentation pond for $1 \mathrm{~h}$. The hydraulic 
loading for each belt was $5 \mathrm{~m}^{3} \mathrm{~d}^{-1}$, and the hydraulic retention time was $3 \mathrm{~d}$. Basic chemical and physical parameters and the concentrations of the main pollutants in the influent and effluent were monitored bimonthly during the study period, from August 2005 to June 2008. Three replicates of water samples were collected at each sampling time. The $\mathrm{pH}$ value, concentrations of dissolved oxygen (DO), suspended substance (SS), chemical oxygen demand (COD), biological oxygen demand over $5 \mathrm{~d}\left(\mathrm{BOD}_{5}\right)$, total nitrogen (TN), ammonia-nitrogen $\left(\mathrm{NH}_{3}-\mathrm{N}\right)$, total phosphorus (TP) and soluble phosphate (SP) were determined following the standard methods for analysis of water and wastewater (APHA 1989).

Sample collection and analysis

In June 2008, the juvenile nutritive roots of 3 individual mangrove plants and the surface soil (0 to $10 \mathrm{~cm}$ layer) full of roots (called rhizosphere soil) were collected, once each, at $0,5,10,15,20,25$ and $30 \mathrm{~m}$ distances from the inlet. Fine root samples were cleared in $10 \% \mathrm{w} / \mathrm{v}$ potassium hydroxide $(\mathrm{KOH})$ at $90^{\circ} \mathrm{C}$ for $40 \mathrm{~min}$ and then stained with trypan blue. The total colonization of AMF (TC\%) calculated by summing the number of occurrences of vesicles and arbuscules or hyphae (including times when the structures occurred together as a single record), hyphal colonization ( $\mathrm{HC} \%)$, vesicle colonization (VC\%) and arbuscular colonization (AC\%) were assessed using the magnified intersection method (McGonigle et al. 1990). Then 200 intersects on 40 root segments were scored under a compound microscope (Carl Zeiss, Axiostar plus). AMF spores from the rhizosphere soil sample ( $20 \mathrm{~g}$, air-dried) were obtained following the wet sieving and decanting method (An et al. 1990). Intact and healthy spores were counted to assess the density of the AMF spores. Air-dried samples were used in this study because of the distance between the field site and the laboratory. Care was taken when drying soil samples to reduce the loss in viability of spores.

\section{Expt 2: Greenhouse experiment}

\section{Experimental design}

It is difficult to find a large area near the municipal sewage discharge point that is also close to the foreshore region where mangroves naturally colonize. Because of space limitations, municipal sewage collected from surrounding premises was only discharged to the treatment belt, and tap water control was not applied in Expt 1. A supplementary, smallscale greenhouse experiment was therefore conducted to evaluate the effects of sewage discharge on AMF colonization, with comparison to the tap water control. A constructed wetland system made of 18 PVC pots, each with a dimension of $50 \mathrm{~cm}$ (length) $\times 35 \mathrm{~cm}$ (width) $\times 25 \mathrm{~cm}$ (depth), filled with gravel (bottom, $5 \mathrm{~cm}$ deep) and mangrove sand (surface, $20 \mathrm{~cm}$ deep), was built and kept in a greenhouse. In order to better simulate the natural conditions, no extra AMF inoculums were added to the planting substrates. Water was pumped though a rubber pipe set at the bottom of each pot, with the overflow directed in an upward direction. Similar to the field experiment, the gravel, sand and pipes were not sterilized. The 18 pots were divided into 6 groups, each in triplicate, and arranged in a randomized, complete block design with 2 factors, plant species (Kandelia obovata, Aegiceras corniculatum and without plant) and treatments (wastewater treatment and tap water control). Because of the limited availability of plant materials, 2-yr-old individuals of $K$. obovata or A. corniculatum, instead of 1-yr-old plants as used in Expt 1, were utilized. To enable a better comparison between the results obtained from field and greenhouse experiments, plant coverage in Expt 2 was similar to that in Expt 1, with 15 plants transplanted from the nursery to each pot in September 2007 for Expt 2. The wastewater used in the second experiment was the same as that in Expt 1. Tap water of the same volume was discharged into the tap water control pots. The hydraulic loading for each pot was $5 \mathrm{~m}^{3} \mathrm{~d}^{-1}$.

Harvest and measurements

At the end of the 9 mo experiment, 4 plants of Kandelia obovata or Aegiceras corniculatum, from each pot, were harvested and the roots were carefully separated from the soil. Root samples were used to determine the intensity of AMF colonization, and rhizosphere soil (5 to $15 \mathrm{~cm}$ ) was used for the determination of the density of AMF spores, using the same methods described in Expt 1.

\section{Statistical analysis}

A parametric 1-way ANOVA, followed by a least significant difference (LSD) test at a 5\% confidence 
level, was used to determine any differences in AMF colonization intensity and spore density collected at the different distances from the inlet of each mangrove belt. The same test was used to compare the colonization intensity and spore density measurements between wastewater treatment and the tap water control in the greenhouse experiment. Two-way ANOVA was applied to analyse the effects of plant species and wastewater treatment on the AMF colonization intensity and spore density, with distance from the inlet as the covariate in Expt 1. The effects of plant species, wastewater treatment and their interactions in Expt 2 were also analysed using 2-way ANOVA. The differences between influent and effluent properties for each host plant were compared by a paired $t$-test at a Bonferonni-corrected significance level. All statistical analyses were performed using the commercial software SPSS 16.0.

\section{RESULTS}

\section{AMF colonization intensity and spore density in the constructed mangrove belt (Expt 1)}

In both mangrove belts, the concentrations of COD, BOD 5 and nutrients ( $\mathrm{TN}, \mathrm{NH}_{3}-\mathrm{N}$, TP and SP) in the effluent were significantly lower than that in the influent (Table 1), indicating that wetland belts gradually purified municipal sewage as it passed through. The removal of organic matter and nutrients ( $\mathrm{N}$ and $\mathrm{P}$ ) amounted to between 50 and $70 \%$ for both constructed wetlands. Typical AM structures (hyphae, vesicle and arbuscules) were observed in most of the root samples of Kandelia obovata and Aeqiceras corniculatum, collected at different distances along the belt (Figs. 1 \& 2). No typical structures of dark septate endophytes were found. In the $A$. corniculatum belt, the total colonization of AMF, hyphal colonization, vesicle colonization and arbuscular colonization were significantly lower in the roots of the plants closer to the inlet than in those further away from the influent (Fig. 1). Similar trends were observed in the constructed $K$. obovata wetland belt (Fig. 2), although the AMF colonization intensities in the roots of $K$. obovata (TC\%: 2.5-22.5\%, HC\%: 2.5-15.5\%, VC\%: 0-7.4\% and AC\%: $0-2.8 \%$ ) were generally lower than those in the roots of $A$. corniculatum (TC\%: 15.5-63.5\%, HC\%: 13.5-48.0\%, VC\%: 3.5-27.5\% and $\mathrm{AC} \%: 1.0-18.0 \%)$. In both belts, the $\mathrm{AMF}$ hypha was the dominant structure in the roots of plants close to the inlet, while the vesicle and arbuscular structures were either rarely observed or absent. This implies that the AMF vesicle and arbuscular structures were more sensitive to wastewater than the hyphal structure. Results from 2-way ANOVA showed that the effects of plant species and wastewater on the AMF colonization intensities were statistically significant ( $\mathrm{p}<0.01$; Table 2$)$.

In both constructed wetland belts, AMF spores were recorded in most of the soil samples, but the spore densities were comparatively low, $<10$ spores per $20 \mathrm{~g}$ soil (Fig. 3). AMF spores distributed randomly, with no significant difference in spore densities among the soil samples collected across the inlet ( $p>0.05)$. Significant differences in spore densities did not occur between the 2 wetland belts either $(p>$ 0.05). Two-way ANOVA also showed that neither plant species nor wastewater treatments had any significant effects on the density of AMF spores ( $p>$ 0.05; Table 2). 


\section{A. corniculatum}
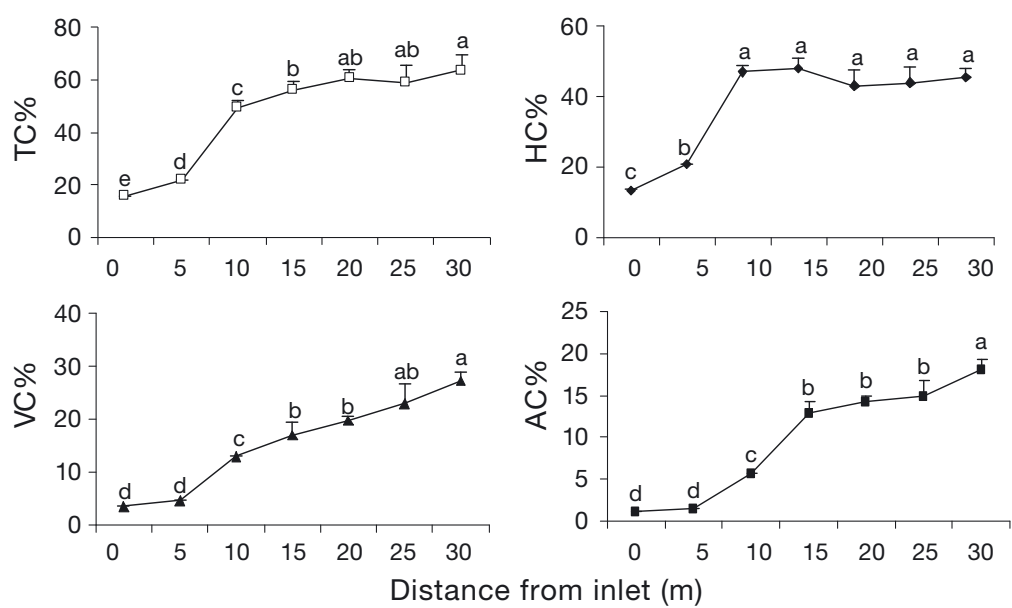

Fig. 1. Colonization intensity of arbuscular mycorrhizal fungi (AMF) in the roots of Aegiceras corniculatum at different distances from the sewage inlet in the constructed mangrove belt. Different letters in each panel indicate the colonization intensities of AMF in the roots of the host species are significantly different at the 0.05 probability level according to 1 -way ANOVA. TC\%: percent total colonization rate (calculated by summing the number of occurrences of vesicles, arbuscules, or hyphae, including times when the structures occurred together as a single record); $\mathrm{HC} \%$ : percent colonization rate of hyphae; $\mathrm{VC} \%$ : percent colonization rate of vesicles; $\mathrm{AC} \%$ : percent colonization rate of arbuscules

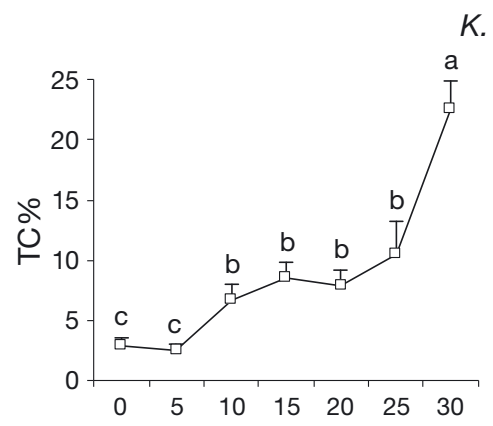

\section{K. obovata}
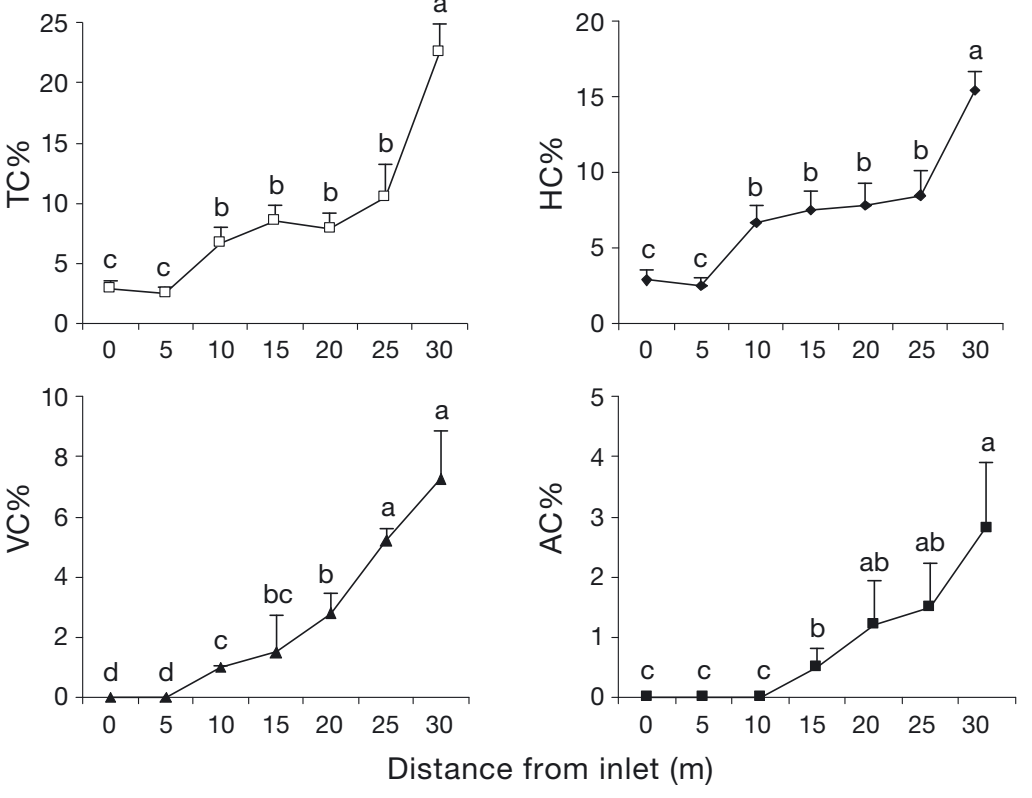

Fig. 2. As above, but for Kandelia obovata

\section{AMF colonization intensity and spore density in the greenhouse experiment (Expt 2)}

The AMF colonization intensities (hyphal, vesicle, arbuscular and total colonization percentages) in mangrove roots, irrespective as to whether it was
Aegiceras corniculatum or Kandelia obovata, in wastewater treatment, were significantly lower than those in the tap water control ( $\mathrm{p}<0.01$ ) (Fig. 4), indicating that wastewater discharge inhibited the symbiosis between AMF and mangrove species. $\mathrm{TC} \%$ and $\mathrm{VC} \%$ in $A$. corniculatum roots were significantly higher than those in $K$. obovata roots, both in the control and the wastewater treatments. When comparing the results between Expts 1 and 2, the AMF colonization intensities for both A. corniculatum and $K$. obovata were at similar levels (Figs. 1, 2 \& 4). Results from 2-way ANOVA showed that the effects of plant species and wastewater on AMF colonization intensities were statistically significant (Table 2), except for the effect of wastewater on $\mathrm{HC} \%(\mathrm{p}>0.05)$. However, 2-way ANOVA showed that neither species nor wastewater treatment had any significant effects on the density of AMF spores (Table 2), and the AMF spore densities in the samples collected from all pots were relatively low (most were $<10$ spores per 20 g soil; Fig. 5).

\section{DISCUSSION}

Many environmental factors have the potential to affect the colonization of AMF in host species (Smith \& Read 2008). In terrestrial ecosystems, high $\mathrm{P}$ supplies suppress the symbiosis between AMF and plants (Smith et al. 2011), which could be interpreted as an active strategy of the plant to limit carbohydrate consumption of the fungus by inhibiting its proliferation in roots in which a set of symbiosis-related genes are involved (Breuillin et al. 2010). High N levels also inhibit AMF colonization, as the relative allocation of carbohydrates to AM structures could be reduced by $\mathrm{N}$ enrichment (Johnson et al. 2003), and high concentrations of $\mathrm{NH}_{4}{ }^{+}$could be toxic to AMF colonizing in roots, inhibiting the germination of AMF spores (Cornejo et al. 2007). In wetland ecosystems, AMF colonization could also be affected by a variety of environmental factors, such as hydrological conditions (Miller \& Bever 1999, Wang et al. 2011), nutrients (Wang et al. 2010), $\mathrm{pH}$ and electric-conductivity levels (D'Souza \& 
Table 2. Univariate 2-way ANOVA analyses showing the effects of mangrove species and wastewater treatment on arbuscular mycorrhizal fungi (AMF) colonization intensity and density of AMF spores. Distance was used as a covariate in comparing the effects of host species and wastewater treatment in Expt 1. See Fig. 1 for abbreviations. DS: density of AMF spores (no. per $20 \mathrm{~g}$ soil) ${ }^{*}{ }^{*} \mathrm{p}<0.05{ }_{i}{ }^{* *} \mathrm{p}<0.01$, NS: not significant

\begin{tabular}{|c|c|c|c|c|c|c|c|c|c|c|}
\hline \multirow[t]{2}{*}{ Variables } & \multicolumn{2}{|c|}{ TC\% } & \multicolumn{2}{|c|}{$\mathrm{HC} \%$} & \multicolumn{2}{|c|}{ VC\% } & \multirow{2}{*}{$\begin{array}{c}\mathrm{AC} \% \\
F\end{array}$} & \multicolumn{2}{|c|}{ DS } & \multirow[b]{2}{*}{$\mathrm{df}$} \\
\hline & $F$ & $\mathrm{df}$ & $F$ & df & $F$ & df & & $\mathrm{df}$ & $F$ & \\
\hline \multicolumn{11}{|l|}{ Expt 1} \\
\hline Species & $90.47^{* *}$ & 1 & $78.33^{* *}$ & 1 & $78.36^{* *}$ & 1 & $42.15^{* *}$ & 1 & 3.21 & 1 \\
\hline Wastewater & $60.99^{* *}$ & 6 & $31.67^{* *}$ & 6 & $52.92^{* *}$ & 6 & $27.71^{* *}$ & 6 & 2.23 & 6 \\
\hline \multicolumn{11}{|l|}{ Expt 2} \\
\hline Species & $26.79^{* *}$ & 1 & $22.92^{* *}$ & 1 & $16.94^{* *}$ & 1 & $29.5^{* *} 4$ & 1 & $0.38^{\mathrm{NS}}$ & 2 \\
\hline Wastewater & $15.29^{* *}$ & 1 & $0.47^{\mathrm{NS}}$ & 1 & $41.20^{* *}$ & 1 & $20.51^{* *}$ & 1 & $0.34^{\mathrm{NS}}$ & 1 \\
\hline Interaction & $3.62^{\mathrm{NS}}$ & 1 & $0.08^{\mathrm{NS}}$ & 1 & $10.96^{*}$ & 1 & $18.51^{* *}$ & 1 & $0.88^{\mathrm{NS}}$ & 2 \\
\hline
\end{tabular}

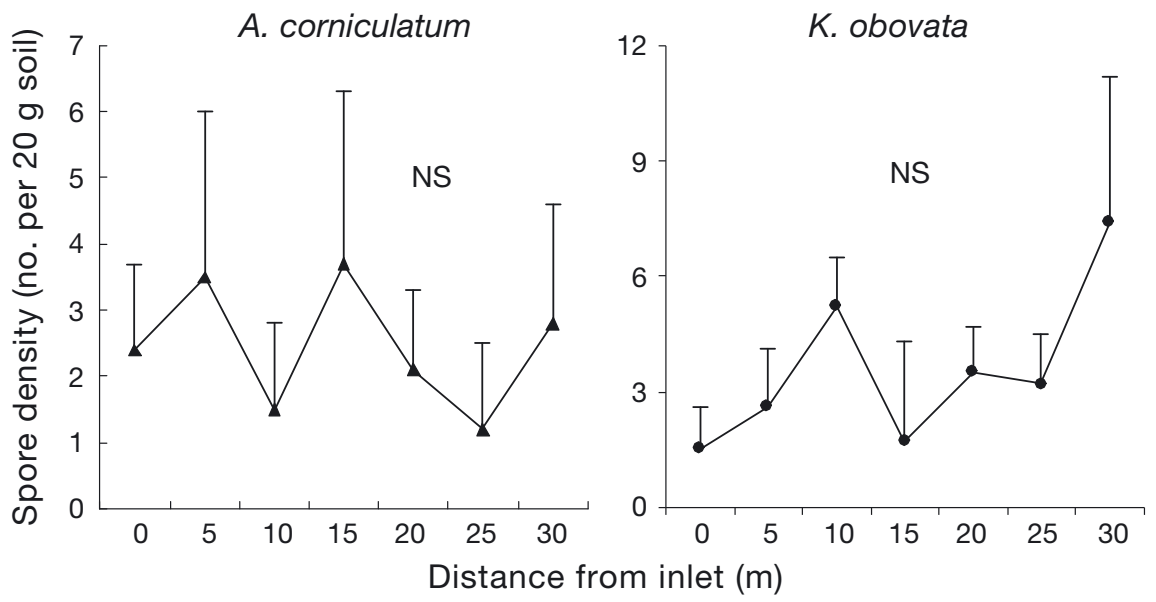

Fig. 3. AMF spore density in the rhizospheric soil at different distances from the sewage inlet in 2 constructed wetland belts planted with Aegiceras corniculatum or Kandelia obovata. NS: not significant
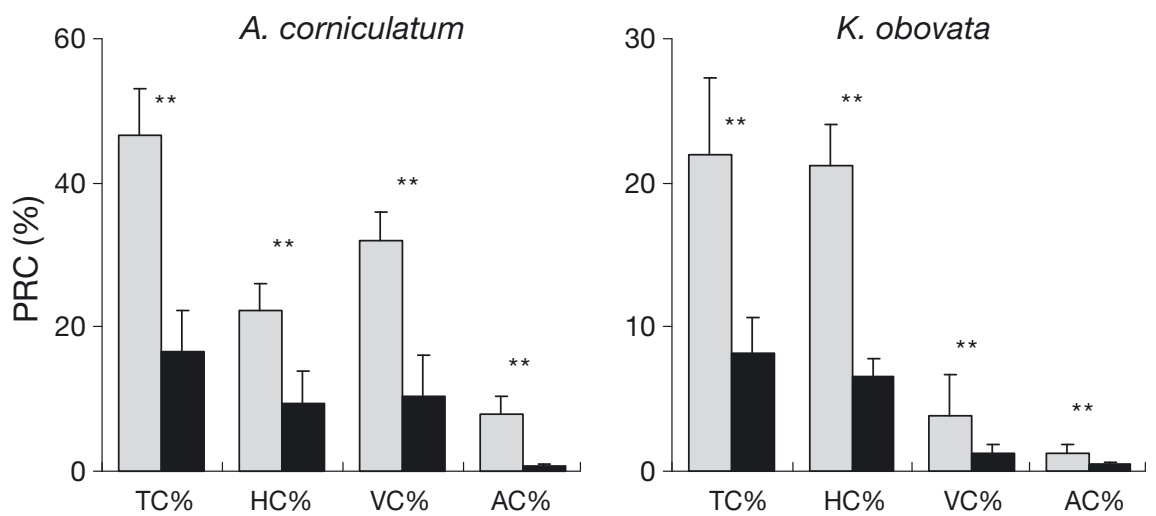

Fig. 4. Percentage root colonization (PRC) of AMF in the roots of Aegiceras corniculatum and Kandelia obovata under wastewater treatment (light grey bars) and tap water control (dark grey bars). See Fig. 1 for abbreviations. ${ }^{* *} p<0.01$

Rodrigues 2013b). The present study revealed that municipal sewage discharge significantly inhibited the colonization intensity (including hyphal, vesicle and arbuscular colonization) of AMF in 2 mangrove species, and the inhibition was least at the effluent, where the concentration of nutrients was lowest. Comparatively high levels of N, P and organic matter in the sewage should partially account for this inhibitory effect, considering that the inhibitory effects of high nutrients on AMF have been widely reported in terrestrial ecosystems (Hodge et al. 2010, Fitter et al. 2011). Further, in wetland ecosystems, the survival of AMF relies on the oxygen provided by the root of wetland plants under flood conditions (Miller \& Bever 1999, Wang et al. 2010). Brzezinska et al. (2006) found that the discharge of wastewater rich in nutrients and organic matter stimulates microbial activities and consumption, which leads to rapid depletion of oxygen in soil. Similarly, wastewater may decrease the radial oxygen loss of the roots of mangrove species and reduce the amount of oxygen released to either the rhizosphere or the root's surroundings (Pi et al. 2010a,b). The decrease in oxygen content in the rhizosphere of mangrove plants might explain the inhibitory effects of sewage on the colonization of AMF.

The present study showed that AMF vesicles and arbuscules were more sensitive to wastewater discharge than were hyphal structures. Smith \& Read (2008) reported that the formation of AMF vesicles and arbuscules in roots is achieved by differentiation, such as twisting, branching and expansion of AMF hyphae in the inner cortical cells. The higher sensitivities of vesicles and arbuscules implies that sewage discharge might inhibit their formation processes of hyphal structures; however, the details and the mechanisms involved remain unknown. So 


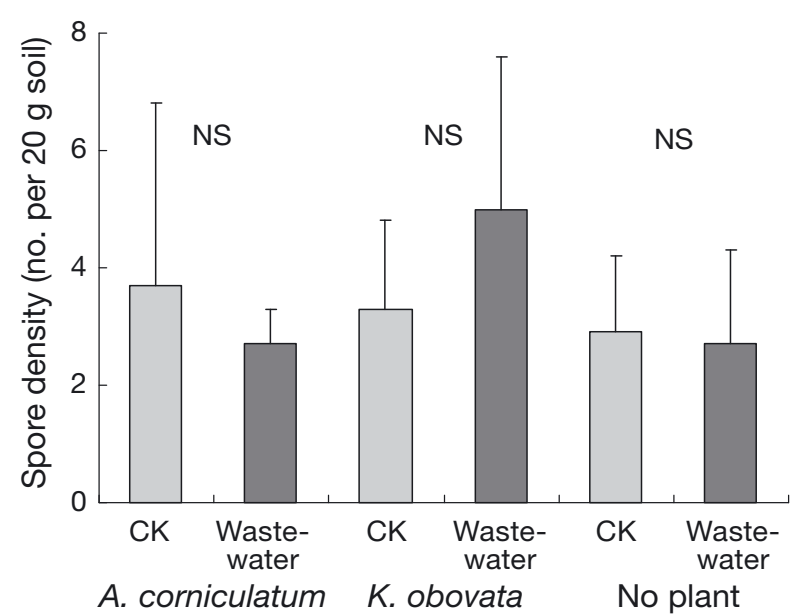

Fig. 5. Spore density of AMF in the soil of the wastewater treatment and tap water control (CK) in the 3 constructed wetland belts with Aegiceras corniculatum, Kandelia obovata, or no plants. NS: not significant

far, only the study by Pawlowska \& Charvat (2004) reported the effects of heavy metal stress on different stages of AMF life history within roots. The role of AMF in mangrove ecosystems is still largely unknown, though Wang et al. (2010) found that AMF can improve the nutrient absorption of some mangrove plants. Therefore, it is difficult to evaluate, comprehensively, the ecological consequences of AMF inhibition (or extinction) in mangrove ecosystems caused by sewage discharge. Nevertheless, it is reasonable to believe that the inhibitory effects of sewage discharge on AMF colonization, especially on the arbuscular and vesicle structures, are related to the nutrient exchanges between AMF and their host plants and the nutrient storage for AMF, respectively (Smith \& Smith 2011). This inhibition would greatly reduce the potentially beneficial effects of AMF on mangrove ecosystems. The effects of sewage discharge on the growth of mangrove plants have been evaluated in several studies (Wong et al. 1995, Herteman et al. 2011), but no congruent view has been reached. The results of the present study provide knowledge important for managing the conservation and restoration of mangrove forests, especially those subject to human disturbance.

Strong effects of the host species on AMF colonization were found in the present study, and AMF colonization intensities in Aegiceras corniculatum were significantly higher than in Kandelia obovata. The effects of host species on AM symbiosis could be attributed to many factors, including the differences in plant physiology, root morphological structure and the components of root exudates (Smith \& Read 2008). Wang et al. (2010) found little or no AMF colonization on the young seedlings of some mangrove species, where the aerenchyma was not yet well developed. Nutrient conditions and planting space of host plants could also influence AM symbiosis, since this could affect the allocation of $\mathrm{C}$ sources from plants to the fungal symbiont (Smith \& Read 2008). The higher AMF colonization intensity in A. corniculatum roots could be partly due to the release of more oxygen, indicated by the higher concentration of dissolved oxygen and lower negative redox potential in the constructed wetland belt planted with A. corniculatum wetland (Table 1). The mechanism involved and the importance of oxygen in AMF merits further research. Additionally, A. corniculatum, when compared to K. obovata, had higher efficiency in removing $\mathrm{N}$ and $\mathrm{P}$ from sewage (Table 1 ). This may also contribute to the higher AMF colonization intensity within the roots of $A$. corniculatum, since high nutrient levels could inhibit AMF colonization (Fitter et al. 2011). Further studies are still needed to elucidate the reasons behind this.

In the present study, the density of AMF spores was comparatively low and spores were distributed randomly in the constructed wetland belt. In recent field investigations of the mangrove ecosystems in Shenzhen and Zhuhai, China (Y. Wang et al. unpubl.) similar results were obtained. The environmental factors affecting the distribution of AMF spores have been widely reported, but mostly in terrestrial ecosystems (Oehl et al. 2009). Only a few researchers have investigated the distribution pattern of AMF spores in wetland ecosystems (Miller \& Bever 1999, Wilde et al. 2009). D'Souza \& Rodrigues (2013b) found that the spore density and species richness of AMF in a mangrove system in Goa, India, was co-affected by season and host plants. The hydrological conditions, such as soil moisture and water depth, were also very important in determining the distribution patterns of AMF spores in wetland ecosystems (Miller \& Bever 1999, Wilde et al. 2009). In the present study, no significant change over distances from the influent to the effluent, nor between wastewater treatment and control was determined, which might be partially due to the low AMF spore density throughout the study. Further, considering the wide application of sand and gravel in the construction of the wetlands, the low AMF spore density and their random distribution pattern might be related to the frequent water irrigation. More in-depth studies on why the present mangrove habitats had such low AMF spore counts and what role AMF colonization plays in mangrove ecosystems, particularly those with high levels of sewage pollution, should be carried out. 
In recent decades, constructed wetlands have been increasingly used for wastewater treatment due to their low maintenance requirements and construction costs (Kivaisi 2001). As the major component of a constructed wetland, wetland plants play an important role in removal of contaminants (Vymazal 2011). In the present study, constructed wetlands planted with either Kandelia obovata or Aegiceras corniculatum both showed high efficiency in the removal of organic matter and nutrients (Table 1). These results agree with previous findings that mangrove plants, due to their fast growth rate, high demand for nutrients and rich oxygen supply from their extensive roots and aerial root system, are capable of removing wastewater-borne pollutants efficiently (Wong et al. 1997, Yang et al. 2008, Zhang et al. 2010). Constructed mangrove wetland has a high application potential in wastewater treatment.

Acknowledgements. This research was financially supported by the National Natural Science Foundation of China (31371567), the Foundation for Distinguished Young Talents in Higher Education of Guangdong Province (2012LYM_ 0049), the Science Foundation on Cultivating Young Teachers from South China Normal University, the Project of Science and Technology of Guangdong Province (2010 B020311005), the Open Research Fund Program from the Guangdong Key Laboratory of Plant Resources (plant01k15), the Research Fund Program of Guangdong Provincial Key Laboratory of Environmental Pollution Control and Remediation Technology and the Foundation of Human Settlements and Environment Commission of Shenzhen Municipality (2009). The study sponsors had no role in study design, data collection, data analysis, data interpretation, or writing of the report. The authors thank the staff in the Futian-CityU Mangrove Research and Development Centre for their assistance in field samplings. We also thank the anonymous reviewers for their thoughtful advice regarding our manuscript.

\section{LITERATURE CITED}

An ZQ, Hendrix JW, Hershman DE, Henson GT (1990) Evaluation of the 'most probable number' (MPN) and wet sieving methods for determining soil-borne populations of endogonaceous mycorrhizal fungi. Mycologia 82:576-581

APHA (American Public Health Association) (1989) Standard methods for the examination of water and wastewater, 17th edn. APHA, Washington, DC

- Breuillin F, Schramm J, Hajirezaei M, Ahkami A and others (2010) Phosphate systemically inhibits development of arbuscular mycorrhiza in Petunia hybrida and represses genes involved in mycorrhizal functioning. Plant J 64: 1002-1017

> Brzezinska M, Tiwari SC, Stepniewska Z, Nosalewicz M, Bennicelli RP, Samborska A (2006) Variation of enzyme activities, $\mathrm{CO}_{2}$ evolution and redox potential in an Eutric Histosol irrigated with wastewater and tap water. Biol Fertil Soils 43:131-135

Cannicci S, Bartolini F, Dahdouh-Guebas F, Fratini S and others (2009) Effects of urban wastewater on crab and mollusc assemblages in equatorial and subtropical mangroves of East Africa. Estuar Coast Shelf Sci 84:305-317

> Chen QH, Tam NFY, Shin PKS, Cheung SG, Xu RL (2009) Ciliate communities in a constructed mangrove wetland for wastewater treatment. Mar Pollut Bull 58:711-719

> Cornejo P, Borie F, Rubio R, Azcón R (2007) Influence of nitrogen source on the viability, functionality and persistence of Glomus etunicatum fungal propagules in an Andisol. Appl Soil Ecol 35:423-431

D'Souza J, Rodrigues BF (2013a) Biodiversity of arbuscular mycorrhizal (AM) fungi in mangroves of Goa in West India. J For Res 24:515-523

> D'Souza J, Rodrigues BF (2013b) Seasonal diversity of arbuscular mycorrhizal fungi in mangroves of Goa, India. Int J Biodiver, doi:10.1155/2013/196527

> Das S, Vincent JR (2009) Mangroves protected villages and reduced death toll during Indian super cyclone. Proc Natl Acad Sci USA 106:7357-7360

> Fitter AH, Helgason T, Hodge A (2011) Nutritional exchanges in the arbuscular mycorrhizal symbiosis: implications for sustainable agriculture. Fungal Biol Rev 25: $68-72$

> Herteman M, Fromard F, Lambs L (2011) Effects of pretreated domestic wastewater supplies on leaf pigment content, photosynthesis rate and growth of mangrove trees: a field study from Mayotte Island, SW Indian Ocean. Ecol Eng 37:1283-1291

- Hodge A, Fitter AH (2010) Substantial nitrogen acquisition by arbuscular mycorrhizal fungi from organic material has implications for $\mathrm{N}$ cycling. Proc Natl Acad Sci USA 107:13754-13759

> Hodge A, Helgason T, Fitter AH (2010) Nutritional ecology of arbuscular mycorrhizal fungi. Fungal Ecol 3:267-273

> Johnson NC, Rowland DL, Corkidi L, Egerton-Warburton LM, Allen EB (2003) Nitrogen enrichment alters mycorrhizal allocation at five mesic to semiarid grasslands. Ecology 84:1895-1908

Kivaisi AK (2001) The potential for constructed wetlands for wastewater treatment and reuse in developing countries: a review. Ecol Eng 16:545-560

Lin P (1999) Mangrove ecosystem in China. Scientific Press, Beijing

Lin X, Feng Y, Zhang H, Chen R, Wang J, Zhang J, Chu H (2012) Long-term balanced fertilization decreases arbuscular mycorrhizal fungal diversity in an arable soil in North China revealed by 454 pyrosequencing. Environ Sci Technol 46:5764-5771

McGonigle TP, Miller MH, Evans DG, Fairchild GL, Swan JL (1990) A new method which gives an objective measure of colonization of roots by vesicular-arbuscular mycorrhizal fungi. New Phytol 115:495-501

> Miller SP, Bever JD (1999) Distribution of arbuscular mycorrhizal fungi in stands of the wetland grass Panicum hemitomon along a wide hydrologic gradient. Oecologia 119:586-592

Miller SP, Sharitz RR (2000) Manipulation of flooding and arbuscular mycorrhiza formation influences growth and nutrition of two semiaquatic grass species. Funct Ecol 14: 738-748

> Oehl F, Sieverding E, Ineichen K, Mäder P, Wiemken A, Boller T (2009) Distinct sporulation dynamics of arbuscular mycorrhizal fungal communities from different agroecosystems in long-term microcosms. Agric Ecosyst Environ 134:257-268 
Pawlowska TE, Charvat I (2004) Heavy-metal stress and developmental patterns of arbuscular mycorrhizal fungi. Appl Environ Microbiol 70:6643-6649

Pi N, Tam NFY, Wong MH (2010a) Effect of wastewater discharge on root anatomy and radial oxygen loss (ROL) patterns of three mangrove species in southern China. Int J Phytoremediation 12:468-486

Pi N, Tam NFY, Wong MH (2010b) Effects of wastewater discharge on formation of Fe plaque on root surface and radial oxygen loss of mangrove roots. Environ Pollut 158: 381-387

Polidoro BA, Carpenter KE, Collins L, Duke NC and others (2010) The loss of species: mangrove extinction risk and geographic areas of global concern. PLoS ONE 5:e10095

Sáinz MJ, Taboada-Castro MT, Vilarinó A (1998) Growth, mineral nutrition and mycorrhizal colonization of red clover and cucumber plants grown in a soil amended with composted urban wastes. Plant Soil 205:85-92

Sengupta A, Chaudhuri S (2002) Arbuscular mycorrhizal relations of mangrove plant community at the Ganges river estuary in India. Mycorrhiza 12:169-174

Sheue CR, Liu HY, Yong JWH (2003) Kandelia obovata (Rhizophoraceae), a new mangrove species from eastern Asia. Taxon 52:287-294

Smith SE, Read DJ (2008) Mycorrhizal symbiosis. Academic Press, Cambridge

Smith SE, Smith FA (2011) Roles of arbuscular mycorrhizas in plant nutrition and growth: new paradigms from cellular to ecosystem scales. Annu Rev Plant Biol 62:227-250

Smith SE, Jakobsen I, Grønlund M, Smith FA (2011) Roles of arbuscular mycorrhizas in plant phosphorus nutrition: interactions between pathways of phosphorus uptake in arbuscular mycorrhizal roots have important implications for understanding and manipulating plant phosphorus acquisition. Plant Physiol 156:1050-1057

van der Heijden MGA, Bardgett RD, van Straalen NM (2008) The unseen majority: soil microbes as drivers of plant diversity and productivity in terrestrial ecosystems. Ecol

Editorial responsibility: Kedong Yin,

Nathan, Australia
Lett 11:296-310

van Diepen LTA, Lilleskov EA, Pregitzer KS (2011) Simulated nitrogen deposition affects community structure of arbuscular mycorrhizal fungi in northern hardwood forests. Mol Ecol 20:799-811

Vymazal J (2011) Plants used in constructed wetlands with horizontal subsurface flow: a review. Hydrobiologia 674: 133-156

Wang YT, Qiu Q, Yang ZY, Hu ZJ, Tam NFY, Xin GR (2010) Arbuscular mycorrhizal fungi in two mangroves in South China. Plant Soil 331:181-191

> Wang Y, Huang Y, Qiu Q, Xin G, Yang Z, Shi S (2011) Flooding greatly affects the diversity of arbuscular mycorrhizal fungi communities in the roots of wetland plants. PLoS ONE 6:e24512

Wang Y, Qiu Q, Xin G, Yang Z, Zheng J, Ye Z, Li S (2013) Heavy metal contamination in a vulnerable mangrove swamp in South China. Environ Monit Assess 185: 5775-5787

> Wilde P, Manal A, Stodden M, Sieverding E, Hildebrandt U (2009) Biodiversity of arbuscular mycorrhizal fungi in roots and soils of two salt marshes. Environ Microbiol 11: 1548-1561

Wong YS, Lan CY, Chen GZ, Li SH, Chen XR, Liu ZP, Tam NFY (1995) Effect of wastewater discharge on nutrient contamination of mangrove soils and plants. Hydrobiologia 295:243-254

> Wong YS, Tam NFY, Lan CY (1997) Mangrove wetlands as wastewater treatment facility: a field trial. Hydrobiologia 352:49-59

> Yang Q, Tam NFY, Wong YS, Luan TG and others (2008) Potential use of mangroves as constructed wetland for municipal sewage treatment in Futian, Shenzhen, China. Mar Pollut Bull 57:735-743

> Zhang J, Liu J, Ouyang Y, Liao B, Zhao B (2010) Removal of nutrients and heavy metals from wastewater with mangrove Sonneratia apetala Buch-Ham. Ecol Eng 36: 807-812

Submitted: May 31, 2013; Accepted: November 25, 2013 Proofs received from author(s): January 29, 2014 